\title{
Analyzing the Dynamics Between Macroeconomic Variables and the Stock Indexes of Emerging Markets, Using Non-linear Methods
}

\author{
Huthaifa Alqaralleh ${ }^{1}$, Ahmad Al-Majali ${ }^{1}$ \& Abeer Alsarayrh ${ }^{1}$ \\ ${ }^{1}$ Department of Economics, Business and Finance, Mutah University, Jordan \\ Correspondence: Huthaifa Alqaralleh, Department of Economics, Business and Finance, Mutah University, Jordan.
}

Received: December 15, 2020

Accepted: January 12, 2021

Online Published: January 20, 2021

doi:10.5430/ijfr.v12n3p193

URL: https://doi.org/10.5430/ijfr.v12n3p193

\begin{abstract}
This study empirically considers five emerging markets from January 1995 to July 2019 to see whether nonlinearity helps to investigate responses to macroeconomic shocks in stock prices. With Vector Smooth Transition Regression, it uses real effective exchange rates, interbank interest rates, industrial production indices, and stock market returns. It confirms that nonlinearity in emerging markets may stem from their susceptibility to high volatility arising from political and geopolitical turnovers or global financial liquidity. It highlights significant differences in the asymmetric patterns. Some emerging markets respond asymmetrically to macro-variables, while others suggest that stock returns adjust from high or low towards the middle ground. Policy-makers seeking acceptable, accessible, sustainable and replicable actions that help stakeholders to invest may get help from our study to understand the properties of emerging markets central to each country's economic activity.
\end{abstract}

Keywords: asymmetric behaviour, vector smooth transition regression, stock return, macroeconomic, emerging markets

\section{JEL Classification: C58, F31, E32, E4}

\section{Introduction}

The financial markets have emerged as powerful platforms for economic development due to their crucial role in attracting external and internal capitals alike (Nazir et al. 2010; Fama, 1965, among others). Moreover, from the money demand point of view, these markets are considered important channels that meet people's financial needs at the least possible cost and risk. The latter is possible thanks to their capacity to build economic units which communicate with each other, spreading more knowledge than ever before about financial issues and working out firms' performance by inference. The prices of stocks are also published, which in turn plays a major role in making investment decisions (Sir, 2012; Ferson and Harvey, 1993; Balvers at al., 1990).

Recent developments in analyzing the financial market have heightened the need to understand the influence of macroeconomic variables. On the one hand, policymakers shed light on stock price fluctuations in order to create the appropriate policy to control economic recessions and maintain stability in the financial markets (e.g. Chen et al., 1986). On the investment decision side, investors are constantly keen to track the changes in stock markets in order to make profits or at least to avoid a loss (see, e.g., Jamaludin et al., 2017; Singh, 2016).

A considerable amount of literature has been published on the role of financial and macroeconomic variables in predicting stock market returns. For example, the seminal work of Fama and French (1989) highlight the significant effect of interest rates, inflation and output growth on predicting equity returns in the US (see also Fama, 1981). In their influential paper, Chen et al. (1986) illustrate that the industrial production index growth is a strong candidate for being a risk factor, while inflation plays a minor role. In the same way, Lamont (2000) shows that portfolios tracking industrial production and consumption earn abnormal returns compared with those at that merely track inflation. Similarly, Chuang et al. (2007) examine whether money supply and budget deficit are important in predicting stock returns. Their results suggest that a long-run equilibrium relationship exists between macroeconomic policies and stock prices. However, in the short run stock prices do not adjust quickly and fully to changes in either monetary or fiscal policies. Gan et al. (2006) and Liu and Shrestha (2008) find a negative relationship between stock prices and interest rates in the long run, while Pilinkus and Boguslankas (2009) conclude that short term interest rates negatively influence stock market prices. 
The aforementioned studies, however, are limited to examining the interaction between stock returns and macroeconomic variables in a linear regression framework. Recently, a great deal of theoretical discussion has proposed that stock returns may be better characterized by a model that allows for non-linear behavior (Note 1). According to Timmermann (2008), such asymmetry may be due to the data-generating processes for stock price dynamics that change over time, and thus individual models can reveal only evidence of local predictability. Other potential sources of this nonlinearity in stock return may stem from stock return determinants, since the nonlinear type models have been used to consider the behaviour of such macroeconomic and financial variables as the interest rate spread, GDP and the unemployment rate (Sarantis, 2001; Brock and Hommes, 1998; Hsieh, 1991).

Against this background, if one wishes to address asymmetric stock returns, the nonlinear models apply (Enders and Siklos, 2001; Balke and Fomby, 1997). There is a growing body of literature that recognizes such nonlinearity in the stock return. Lin et al. (2018) show that stock prices are closely correlated with economic variables, particularly in the case of small, low-priced and extremely volatile shares with a high book-to-market ratio and excess returns. The latter complexity induces a need to consider nonlinearity when modelling the relationship between such macroeconomic factors and stock returns (see also Yang and Zhou, 2016). An early example is the study by Qi (1999), which investigates this relationship using a neural network model. Guidolin et al. (2018) highlight the central role of nonlinearity when modeling a relationship between macroeconomic variables and stock prices that allows for asymmetry. Signs of nonlinearity have also been reported in several studies (see, e.g., Lardic and Mignon, 2008; Zhang, 2017). A recent study by Lee and Ryu (2018) shows that stock price shocks respond insignificantly to macroeconomic variables under simple ARDL, whereas a significant and negative long-run effect is found for almost every explanatory variable, a market pair under the nonlinear model. The nonlinear ARDL is also used in Alqaralleh (2020), in which the author highlights that responses of stock return to macroeconomic variables are generally asymmetric.

However, the above evidence for such a relationship is inconclusive, since the transition function used to capture fluctuations from the conditional mean of the changes in the return series in the employed nonlinear models is, by definition, symmetric. Therefore, these models cannot explain whether all the switches in the financial market at different times are influenced by changes in the aggregate economic factors. In fact, investors may be prone to diverse degrees of institutional inertia (dependent, for example, on the efficiency of the stock markets in which they operate) and so they adjust with different time lags. Thus, when considering aggregate economic series, the time path of any structural change is liable to be better captured by a model whose dynamics undergo gradual, rather than instantaneous adjustment between regimes (see, e.g. Peters, 1994).

With these drawbacks in mind, the central task of this paper is to answer the following obvious question: Do many stock market returns react simultaneously to a given economic signal? In order to answer this question, we use the Vector Smooth Transition Regression (VSTR) (see Teräsvirta, Van Dijk, and Medeiros, 2005). The main advantage in favor of VSTR models is that a continuum of states between the extremes appears more realistic. In other words, this VSTR-type model allows exactly for gradual change and thus the possibility of modeling different types of market behavior, determined by the magnitude of the returns. Another advantage of such models is that they allow switching behavior to depend upon observable variables.

The VSTR- type model is one of the most common procedures for determining non-linear relationships in macroeconomic time series (see, among others, Granger and Teräsvirta, 1993; 1999). In the financial literature, however, only very few researchers have used this kind of model to study stock market behavior. One study by McMillan (2001) investigates the nonlinearity between stock returns and business cycle variables. Other applications of VSTR models in the financial literature include those by Sarantis (2001), Franses and van Dijk (2000) and Harvey and Mills (2001).

Part of the aim of this paper is to investigate this stock return/macroeconomic nexus in emerging markets. We chose emerging markets because they are more susceptible to crises of high volatility resulting either from political and geopolitical turnovers or an environment of global financial liquidity. Such volatility would result in, first, wide currency swings because these countries have too little power to influence commodities swings, such as in oil or food. Second, a capital outflow leaves its government with the choice of either letting reserves reduce or letting interest rates rise. However, on the one hand, letting reserves flow out can lead to higher inflation and severely threatens the external value of the currency. On the other, raising interest rates keeps inflation low, but has the effect of causing a recession. Over time, this could lead to social unrest, rebellion, and regime change. 
The remainder of this paper is organized as follows. Section 2 describes the dataset employed in this study where economics as well as econometric techniques are used to model the relationship. Section 3 discusses the findings and draws some conclusions.

\section{Data and Descriptive Statistics}

The data employed in this study are monthly data over the period January 1995 to July 2019. This period was chosen to illustrate the macroeconomic variables-stock return nexus during both troubled and tranquil periods in certain countries. As mentioned to the introduction, investigating the macroeconomic variables-stock return nexus in emerging markets is of great interest because these markets are more susceptible to crises. However, for reasons of data availability we consider five markets, namely, those of Brazil, Poland, Mexico, Greece, and Malaysia. We make use of four macroeconomic variables: real effective exchange rate (REER), the interbank interest rate (IR), industrial production index growth (IPI), and stock market returns (SR). The data for all countries is taken from the International Financial Statistics (IFS), and the analytical database of the Organization for Economic Cooperation and Development (OECD).

Table 1 presents the summary statistics for the time series in question. As shown in Panel A of the table, most of these series depart from normal Gaussian distribution. Therefore, the KSS test of Kapetanios et al (2003) was applied since the unit root tests based on the traditional AR model might have resulted in a misleading conclusion. This test computes a first order Taylor series to examine the nonlinear adjustment in time series under the null hypothesis that the stock return series follows a linear unit root process (see, among others, Kapetanios et al, 2003). The results of the KSS test are presented in Panel B of Table 1. At the 5\% level, the null hypothesis of stationarity is rejected, which implies that the adopted stock return series are nonlinearly stationary and, thus, exhibit nonlinear characteristics. It is also worth noting that all the variables in the model were stationary on the level.

Table 1. Descriptive statistics and stationarity

\begin{tabular}{|c|c|c|c|c|c|}
\hline & Brazil & Poland & Mexico & Greece & Malaysia \\
\hline \multicolumn{6}{|c|}{ Panel A; Descriptive Statistics } \\
\hline Skewness & 0.226 & 0.052 & 0.124 & 0.875 & 0.061 \\
\hline Kurtosis & 1.893 & 1.546 & 1.381 & 2.721 & 1.640 \\
\hline JB & {$[0.000]$} & {$[0.000]$} & {$[0.000]$} & {$[0.000]$} & {$[0.000]$} \\
\hline \multicolumn{6}{|c|}{ Panel B; Unit Root Test } \\
\hline KSS Test & 1.679 & 1.036 & 0.927 & 1.572 & 1.112 \\
\hline \multicolumn{6}{|c|}{$\begin{array}{l}\text { Note: the values in [ ] refer to measures of probability according to the Jarque-Bera test for normality. "KSS" } \\
\text { relates to the Kapetanios, Shin and Shell unit root tests. Asymptotic } 5 \% \text { Critical Values of KSS Statistic is - } 2.93 \text {. } \\
\text { It's worth noting that the test is conducted using Stata module proposed by Otero and Smith (2017). }\end{array}$} \\
\hline
\end{tabular}

\section{Modelling the Relationship Between Stock Return and Macro-Variables}

\subsection{The Economic Model}

The issue of incorporating nonlinearity in the relationship between the aggregate stock price level and the macroeconomic variables in an empirical analysis has received considerable critical attention. Drawing on the seminal papers (among others; Yang et al. 2018; Lee and Ryu, 2018; Han et al., 2012; Lee and Ryu, 2013) that highlight the asymmetric response of stock returns to related macroeconomic variables, we see that different variables have been found $\mathrm{n}$ previous studies to be included in order to empirically investigate this relationship. This study uses the following general specification:

$$
S R=\alpha_{0}+\alpha_{1} I P I+\alpha_{2} I R+\alpha_{3} R E E R+\varepsilon_{t}
$$

Where the real effective exchange rate is denoted by REER), the interbank interest rate is IR, the industrial production index growth is IPI, and the stock market returns are defined as SR. From the literature review, the interaction between these variables and stock returns seems to be inconclusive. Below is a detailed explanation for the expected signs of these variables. 


\subsubsection{Real Effective Exchange Rate (REER)}

Many recent studies (e.g. Ratanapakorn and Sharma, 2007; Tripathy, 2011) have demonstrated that the real exchange rate can affect stock prices in several ways. However, the interaction will be different depending on whether the economy imports or exports more and whether it hedges against exchange rate fluctuation (Dimitrova, 2005).

From the macroeconomic perspective, on the one hand, a depreciated currency impacts domestic output positively because it depresses imports and boosts exports. Consequently, investors tend to boost share prices since growing output is seen to indicate a wealthy economy. If, however, a depreciation of the exchange rate creates expectations of inflation for the future, the depreciation tends to curb consumer spending and therefore company earnings (Kwon and Shin, 1999). On the other hand, at the firm level, exchange rate fluctuation may negatively affect the value of firms' stock prices. Loosely speaking, currency depreciation erodes the return on a foreign investor's investment and thus makes investors unwilling to hold assets (Ajayi and Mougoue, 1996).

Taken together, these studies support the notion that stock prices may negatively interact with a real effective exchange rate, especially in countries with emerging markets that are susceptible to crises.

\subsubsection{Interest Rate (IR)}

Interest rates can play an important role in addressing the issue of the movement of stock prices. According to Fama (1981, 1990), interest rates negatively influence stock returns through the discount rate. This negative relationship may also through the higher cost of funding stem indirectly from a rise in interest rates (ceteris paribus), lower future profits, an increase in the discount rate for equity investors; and then a decrease in stock prices. In addition, Bjørnland and Leitemo (2009) claim that interest rates may affect stock markets because monetary policy provides feedback to central banks about what the private sector expects the about future macroeconomic variables to be (see also, Bernanke and Gertler, 2000).

Numerous studies have investigated this relationship in both developing and emerging markets (e.g. Alam,2017; Hussain et al., 2013; Humpe and Macmillan, 2009). All of the studies reviewed here support the hypothesis that stock prices are negatively correlated to interest rates.

\subsubsection{Industrial Production Index Growth (IPI)}

Awareness of the relationship between stock prices and the industrial production index growth is not recent. Much of the literature emphasizes that an increasing industrial production index growth is a positive sign of investors' expectations about future economic performance (Ikoku, 2010, among others). In Fama's seminal work (1990), he argues that future production growth rates reflect certain information about cash flows that informs stock prices. In line with this conclusion, other authors maintain that output growth is the main driving force behind stock market performance because this growth contributes to the ability of firms to generate cash flows (e.g., Humpe and Macmillan, 2009; Nishat and Shaheen, 2004).

Together, these studies suggest a positive relationship between real economic activities, proxied by the industrial production index growth and stock returns.

\subsection{Econometric Model}

Several methods are currently used to assess the relationship between macroeconomic variables and stock prices. In this study, Vector Smooth Transition Regression (VSRT) was selected for its reliability and validity in modeling the interaction between macroeconomic factors and stock market in periods of financial stress (e.g., Alqaralleh, 2019). Moreover, the nonlinear structure of the models leads to important improvements over forecasting with an incorrectly specified linear model (Canepa et al. 2020; Balcilar et al., 2015; Cabrera et al., 2011).

To describe the relationships between these variables, we follow Hubrich and Terasvirta (2013) and make use of the generalization single-equation STR model for the vector case, as follows

$$
S R_{t}=\mathrm{A}_{0}+\mathrm{A}_{1} G\left(\gamma, c ; s_{t}\right)+\sum_{j=1}^{p}\left\{\phi_{j}+G\left(\gamma, c ; s_{t}\right) \psi_{j}\right\} S R_{t-j}+\left[\Gamma+G\left(\gamma, c ; s_{t}\right) \Xi\right] \chi_{t}+\varepsilon_{t}
$$

where $S R_{t}$ is an $m \times 1$ vector of stationary stock return variables; $\mathrm{A}_{0}$ and $\mathrm{A}_{1}$ are $m \times 1$ intercept vectors; $\chi_{t}$ is the $n \times 1$ vector of stationary exogenous regressor including $(R E E R),(I R)$, and (IPI); $\phi_{j}$ and $\psi_{j}$ are $m \times m$ parameter matrices; and $\Gamma$ and $\Xi$ are $m \times n$ parameter matrices.

For a given stationary transition variable $\boldsymbol{s}_{\boldsymbol{t}}$, the $m \times m$ transition matrices have the following form

$$
G_{j}\left(\gamma_{j}, c_{j} ; s_{j t}\right)=\operatorname{diag}\left\{G_{1}\left(\gamma_{1}, c_{1} ; s_{1 t}\right), \ldots, G_{m}\left(\gamma_{m}, c_{m} ; s_{m t}\right)\right.
$$


The transition matrices defined in Equation (2) can be defined as a standard Logistic function (Equation 4) or an Exponential function (Equation 5), viz.

$$
\begin{gathered}
G_{j}\left(\gamma_{j}, c_{j} ; s_{j t}\right)=\left[\frac{1}{1+e^{-\gamma_{j}\left(s_{j t}-c_{j}\right)}}\right] \\
G_{j}\left(\gamma_{j}, c_{j} ; s_{j t}\right)=\left[1-e^{-\gamma_{j}\left(s_{j t}-c_{j}\right)^{2}}\right]
\end{gathered}
$$

The Logistic transition function of the form defined in Equation (4) along with the generalized STR model in Equation (2) yield VLSTR, while plugging Equation (5) into Equation (2) yields VESTAR. In both cases, the regime-specific dynamics governs the transition between 0 and 1 regime, depending on the values of the location parameters $c$ and the smoothness parameter $\gamma$. The delay parameter $d$ of the transition variable can take values in the range of $1 \leq d \leq p$ or $d>p$ (van Dijk, 1999; Siliverstovs, 2005).

The model specification steps of VSTR models generally consist of estimating an appropriate VAR (P) model that can be chosen on the basis of information criteria and a serial correlation test. Next, a set of linearity tests against the nonlinear alternative should be deployed. The latter is usually tested by means of the Taylor expansion-based linearity test from Luukkonen et al. (1988). The third step concerns the type of transition function which can be guided by economic theory, or, alternatively, can involve a procedure suggested in Tsay (1989) and Teräsvirta (1994). Finally, before the estimated VSTR model can be accepted as adequate, it should be subjected to mis-specification tests that include a test for no remaining nonlinearity and the hypothesis of parameter constancy.

\subsection{Estimation Results and Discussion}

In this section, we report the results of the dynamic interaction between stock returns and selected macroeconomic variables. First, the maximal lag order of the VAR(P) model along with an optimal delay parameter are presented in Panel A of Table 2. Interestingly, using the information criterion and the portmanteau test for serial correlation, the persistence of the fitted model was observed to vary in the countries under consideration. However, in all cases, with any shock in macro-variables, the stock returns experience a slow reversion to their mean. It seems possible that these mean reversions are due to the asymmetric response of these stock markets to the macroeconomic shocks.

Such inefficiency in these markets results in a high level of fluctuations, which contribute to features of financial instability such as high persistence, positive dependence, and nonlinearity. Consequently, we test the possibility of this nonlinearity by applying the expression in Luukkonen et al. (1988) as the basis for LM tests. As can be seen from Panel B in Table 2, the hypothesis of linearity is strongly rejected at the 5\% significance level. We therefore conclude that a nonlinear VSTR type model is better able than a VAR (p) model to capture the features of the variables under consideration.

Having rejected the linearity hypothesis, the next step is to validate our hypothesis that the dynamics of stock return and macro-variables can best be modelled using an econometric model which is, by construction, able to capture asymmetric cycles. In this manner, we can do this with the methodology of Van Dijk Et Al (2002), conducting a series of F-tests to test the following hypotheses:

$$
\begin{aligned}
& \mathrm{H}_{01}=\Phi_{4 i}=0 \\
& \mathrm{H}_{02}=\Phi_{3 i}=0=\Phi_{4 i}=0 \\
& \mathrm{H}_{03}=\Phi_{2 i}=\Phi_{3 i}=\Phi_{4 i}=0
\end{aligned}
$$

These hypotheses indicate that the rejection of $\mathrm{H}_{01}$ implies selecting the logistic transition function in Equation (3). If, however, we cannot reject $\mathrm{H}_{01}$, the second part of the sequential test has to be estimated. Rejection of hypothesis $\mathrm{H}_{02}$ implies the selection of the exponential transition function in Equation (4). However, we move to the last part of the sequential test if we cannot reject $\mathrm{H}_{02}$. Rejection of $\mathrm{H}_{02}$ implies the selection of the transition function in Equation (3) and therefore the VLSTR model.

However, Kapetanios (2001) suggests that the choice between various transition functions can be made by comparing the p-values. To this end, the VESTR model is selected when the P-value for $\mathrm{H}_{02}$ is less than $\mathrm{H}_{01}$ and $\mathrm{H}_{03}$; in other cases, the VLSTR model is selected. Accordingly, the results of Table 2 show that the both Poland and Mexico followed the nonlinear behavior of the Exponential VSTR model. A possible explanation for adopting 
EVSTR is that in these markets the stock return similarly adjusts their periods from high to low levels towards the middle ground. The case in Brazil, and Malaysia is, however, interesting because the logistic transition outperforms the exponential one, suggesting an asymmetrical response to the macro-variables.

Table 2. Linearity test and model selection

\begin{tabular}{clllll}
\hline & Brazil & Poland & Mexico & Greece & Malaysia \\
\hline Panel A; Linearity Test & & & & & \\
\hline VAR(P) $=$ & 4 & 6 & 3 & 5 & 4 \\
\hline Optimal delay parameter $(\mathrm{d})$ & $3(0.000)$ & $3(0.001)$ & $3(0.000)$ & $1(0.004)$ & $2(0.000)$ \\
\hline Panel B; LM test for model selection & 0.002 & & & & \\
\hline$H_{04}: \beta_{4 i}=0$ & 0.024 & 0.107 & 0.002 & 0.118 & $0.000^{*}$ \\
\hline$H_{03}: \beta_{3 i}=0$ & $0.000^{*}$ & $0.001^{*}$ & $0.000^{*}$ & 0.240 & 0.001 \\
\hline$H_{02}: \beta_{2 i}=0$ & & 0.123 & 0.046 & $0.003^{*}$ & 0.003 \\
\hline Panel C; Suggested model & & & & & \\
\hline & LVSTR(P) & EVSTR(P) & EVSTR(P) & LVSTR(P) & LVSTR(P)
\end{tabular}

Panel A reports the linearity tests. Note that the selection of the optimal lag, VAR (p)*, was made using the AIC statistic. Panel B The numbers in parentheses refer to the lowest p-value results of the LM-test. Panel C illustrates the best fitted model.

The last step is concerned with estimating and evaluating the VSTR models. Table 3 reports the parameter estimates together with the diagnostic tests. For ease of interpretation, the estimated parameters for expansion and contraction regimes are reported separately. Starting with the overall goodness of fit of the model as shown in panel B, one interesting finding is that the SEs of the nonlinear parts (a high regime) are, generally, smaller than those of the linear parts (a lower regime) confirming the capacity of the nonlinear models to fit the data under scrutiny. Moreover, the nonlinearity in the relationship under investigation is not the outcome of any outliers in the data, since the residuals are normally distributed as suggested by the Jarque-Bera normality test. It is also encouraging to note that in all cases considered in this study there was also no evidence of remaining nonlinearity. In addition, the autocorrelation tests do not reject the null hypothesis of no autocorrelation against the q-order auto-regression for all the estimated models.

Table 3. Estimated parameter

\begin{tabular}{llllll}
\hline & Brazil & Poland & Mexico & Greece & Malaysia \\
\hline Panel A; Estimated Results & & & & \\
\hline Lower Regime & & & & & \\
\hline CONST & $4.725^{* *}$ & $-3.638^{* *}$ & $0.084^{* *}$ & $-0.957^{*}$ & $-3.213^{* *}$ \\
\hline & $(1.585)$ & $(1.127)$ & $(0.037)$ & $(0.244)$ & $(2.033)$ \\
\hline Share_log_d1(t-1) & $-0.344^{* *}$ & $0.485^{* *}$ & -0.044 & $0.174^{*}$ & $-0.119^{* *}$ \\
\hline & $(0.162)$ & $(0.257)$ & $(0.062)$ & $(0.081)$ & $(0.049)$ \\
\hline Share_log_d1(t-2) & $0.315^{* *}$ & -0.753 & -0.035 & -0.131 & $-0.588^{* *}$ \\
\hline Share_log_d1(t-3) & $(0.070)$ & $(0.828)$ & $(0.052)$ & $(0.239)$ & $(0.285)$ \\
\hline & $-0.512^{* *}$ & -0.391 & $-0.079^{* *}$ & $0.216^{* *}$ & $-0.335^{* *}$ \\
\hline IPI(t) & $(0.201)$ & $(0.243)$ & $(0.034)$ & $(0.107)$ & $(0.113)$ \\
\hline & $0.034^{* *}$ & $0.068^{* *}$ & $0.004^{* *}$ & $0.012^{* *}$ & $0.793^{* *}$ \\
\hline
\end{tabular}




\begin{tabular}{llllll}
\hline & $(0.016)$ & $(0.027)$ & $(0.002)$ & $(0.006)$ & $(0.423)$ \\
\hline $\operatorname{IR}(\mathrm{t})$ & $-0.229^{* *}$ & $-0.131^{* *}$ & $-0.030^{* *}$ & -0.018 & $-0.264^{*}$ \\
\hline & $(0.105)$ & $(0.034)$ & $(0.001)$ & $(0.014)$ & $(0.140)$ \\
\hline REER(t) & 0.131 & 0.396 & $0.020^{* *}$ & $0.032^{*}$ & $0.294^{*}$ \\
\hline & $(0.241)$ & $(0.325)$ & $(0.012)$ & $(0.013)$ & $(0.138)$
\end{tabular}

\section{Higher Regime}

\begin{tabular}{|c|c|c|c|c|c|}
\hline CONST & $-4.618 * *$ & $1.005^{* *}$ & $5.373 *$ & $0.653 * *$ & $0.558 *$ \\
\hline & $(2.185)$ & $(0.501)$ & (2.259) & $(0.314)$ & $(0.133)$ \\
\hline \multirow[t]{2}{*}{ Share_log_d1(t-1) } & $0.504 *$ & $-0.666^{*}$ & $0.205^{* *}$ & $0.374 * *$ & $0.378 * *$ \\
\hline & $(0.162)$ & (0.257) & $(0.100)$ & (0.163) & (0.144) \\
\hline \multirow[t]{2}{*}{ Share_log_d1(t-2) } & $-0.415^{*}$ & $0.177 * *$ & $0.407 *$ & $0.398 * * *$ & $0.311 * *$ \\
\hline & $(0.171)$ & $(0.088)$ & $(0.182)$ & $(0.201)$ & $(0.149)$ \\
\hline \multirow[t]{2}{*}{ Share_log_d1(t-3) } & $0.650 *$ & $0.354 * *$ & $0.459^{* *}$ & $-0.163 * *$ & $0.685 * * *$ \\
\hline & $(0.298)$ & $(0.164)$ & $(0.226)$ & $(0.069)$ & $(0.491)$ \\
\hline \multirow[t]{2}{*}{$\operatorname{IPI}(\mathrm{t})$} & $0.135^{*}$ & 0.081 & $0.200^{*}$ & $0.042 * *$ & $0.604 *$ \\
\hline & $(0.030)$ & $(0.069)$ & $(0.042)$ & $(0.017)$ & $(0.283)$ \\
\hline \multirow[t]{2}{*}{$\operatorname{IR}(\mathrm{t})$} & $-0.321 * *$ & $-0.108^{*}$ & $-0.222 * *$ & $-0.032 * *$ & $-0.370 * *$ \\
\hline & $(0.165)$ & $(0.035)$ & $(0.125)$ & $(0.016)$ & $(0.280)$ \\
\hline \multirow[t]{2}{*}{$\operatorname{REER}(\mathrm{t})$} & $-0.128 *$ & $-0.397 *$ & $-0.117 * *$ & $-0.021 * * *$ & -0.014 \\
\hline & $(0.024)$ & $(0.125)$ & $(0.049)$ & $(0.010)$ & $(0.023)$ \\
\hline \multicolumn{6}{|c|}{ Smooth Transition Parameter } \\
\hline \multirow[t]{2}{*}{ Gamma } & $4.810 *$ & $11.564^{*}$ & $19.642^{*}$ & $4.141 *$ & $7.335^{* *}$ \\
\hline & (1.168) & $(5.428)$ & $(6.618)$ & $(1.960)$ & (3.213) \\
\hline \multirow[t]{2}{*}{$\mathrm{C} 1$} & $-0.198 * *$ & $-0.348^{*}$ & $-0.168 * *$ & $-0.029 * *$ & $-0.145 * *$ \\
\hline & $(0.042)$ & $(0.004)$ & $(0.011)$ & $(0.008)$ & $(0.045)$ \\
\hline \multirow[t]{2}{*}{$\mathrm{C} 2$} & & $-0.120 * *$ & $-0.114 * *$ & & \\
\hline & & $(0.005)$ & $(0.011)$ & & \\
\hline
\end{tabular}

\begin{tabular}{llllll}
\hline Panel B; p-values for Misspecification Tests & & & & \\
\hline ARCH (5) Test & 0.453 & 0.112 & 0.214 & 0.151 & 0.144 \\
\hline No Remaining Nonlinearity & 0.259 & 0.782 & 0.479 & 0.137 & 0.201 \\
\hline Parameter Constancy & 0.340 & 0.189 & 0.617 & 0.492 & 0.230 \\
\hline JB & 0.521 & 0.542 & 0.217 & 0.234 & 0.162
\end{tabular}

Panel A reports the estimated parameters. Standard errors of the estimated parameters are given in parentheses. Panel B reports mis-specification tests. $\left.{ }^{*}\right) * *$ ) and $\left.* * *\right)$ relate to the $1 \%, 5 \%$ and $10 \%$ significance levels, respectively.

Coming to the estimated results presented in Table 3, Panel A, it is apparent that the speed of transition between the two regimes is correctly signed and significantly different from zero, indicating a gradual transition between the times of expansion and recession. These results indicate that emerging markets such as Poland and Mexico exhibit a sharper transition, shown by the slope parameter, $\gamma$, which was about 11.5 for Poland and 19.6 for Mexico. This suggests that these markets are more prone to economic fluctuation than are Brazil, Greece, and Malaysia. These 
three are all characterized by a relatively very smooth transition from one regime to another. Another important finding is that the location parameter(s) is also significant in all cases.

Together, these findings can, however, be interpreted in a different way if we denote $F(\cdot)=0$ as the contraction regime and $F(\cdot)=1$ as the expansion time. In the case of Brazil, for example, given that the market at the time of our survey was initially at the equilibrium period with the weights attached to the two pure regimes equal at [0.5, 0.5], one standard deviation positive shock to the $Y_{t-d}$ yielded $F\left(Y_{t-d}\right)=0.46$. Accordingly, we infer that the weight attached to the one regime differed slightly from that of the other regime, in which the linear combination adjustment of the two regimes was [0.46, 0.48], reducing the speed of adjustment only slightly. The case of Mexico is quite different: the speed of adjustment was relatively high since one standard deviation shock to the stock return index yielded a $[-0.21,0.48]$. The same applied to the rest of the emerging markets under consideration.

As regards the estimation of the selected economic variables, the results indicate that the sign of impact was in line with economic theory and the previous studies in both advanced and emerging markets (e.g., Dasgupta, 2012; Humpe and Macmillan, 2009). In specific, the industrial production index growth had a significant positive impact on the stock returns in almost all the emerging markets that we considered. A possible explanation for this is that the volatility of stock returns increases during recoveries and decreases during economic contractions, which in turn contributes to the ability of firms to generate cash flows (see, e.g., Fama, 1981). Exchange rate changes are also statistically significant, implying that a negative shock in the exchange rate increases stock returns, while an increase in the real effective exchange rates reduces stock returns. Moreover, the positive effect of currency depreciation is rather different from the negative effects of currency appreciation in absolute terms, indicating that exchange rate fluctuations are likely to asymmetrically influence the stock returns. A possible theoretical explanation for these results is that currency depreciation leads to improved competitiveness among exporting firms, which in turn will positively affect stock returns (see Hajj et al., 2018; Ho and Odhiambo, 2017; Seong, 2013). Turning now to the short-term interest rate, which is also relatively important in describing returns, we find that the results also highlight the fact that a decrease in the short-term interest rates will depress the stock market. The latter is due to the maturity mismatch between bank assets and liabilities (see, Christie, 1982).

Lagged country stock returns, however, do not add any incremental information; the sign of impact varies across countries. These results reflect those of Sakti and Harun (2013); Ajmi et al. (2014); Ratanapakorn and Sharma, (2007) who also affirm that the nonlinearity results are more credible in the advanced countries because of the possible existence of structural breaks, asymmetry and regime switching in the markets and the relevant economic and financial variables.

\section{Conclusion}

This study set out to examine if the relationship between stock prices and macroeconomic variables is asymmetric and, if so, how this effect occurs. Using a sample of five emerging markets, we analysed monthly data over the period January 1995 to July 2019. The sample period was chosen to investigate the macroeconomic -variables-stock-return nexus during both troubled and tranquil periods in these countries. Because the relationships between variables took shape under the assumption that the behavior of stock markets return reacts simultaneously to a given economic signal, the current examination used the VSTR approach in order to identify the asymmetric reactions between variables.

One of the significant findings from this study is that the linear VAR $(\mathrm{P})$ highlights a possibility of mean reversions, due to the inefficiency of these stock markets. This inefficiency contributes to financial instability, resulting in nonlinearity. The possibility of nonlinearity is further tested using the Taylor expansion-based linearity test from Luukkonen et al. (1988). Another important finding is that in both Poland and Mexico the stock returns similarly adjust their periods from high to low levels towards the middle ground. By contrast, the findings for Brazil, Greece, and Malaysia suggesting an asymmetrical response to the macro-variables. Another interesting finding is that the selected economic variables have the expected sign of impact in line with economic theory and the previous literature.

It may be hypothesized that the stock prices-macroeconomic -variables nexus is more likely than not to be modelled in a nonlinear fashion. These findings may help us to understand how the properties of emerging markets at the center of a country's economic activity may inform policy makers on the course of acceptable, accessible, and sustainable and replicable actions that help stakeholders to invest.

Despite these promising results, some questions remain. Future studies might investigate the role of other macroeconomic variables that would provide information about the stock return. Further study would also consider 
other time series characteristics, such as volatility, in order to obtain better insight into the generation of returns. Further research could be also developed to determine the capability of such nonlinear structure of the models in the predictability of the stock return.

\section{Data Availability Statement}

Data supporting the findings of this study are available from the corresponding author on request.

\section{References}

Abhyankar, A., Copeland, L. S., \& Wong, W. (1997). Uncovering nonlinear structure in real-time stock-market indexes: the S\&P 500, the DAX, the Nikkei 225, and the FTSE-100. Journal of Business \& Economic Statistics, 15(1), 1-14. https://doi.org/10.1080/07350015.1997.10524681

Ajayi, R. A., \& Mougoue, M. (1996). On the dynamic relation between stock prices and exchange rates. Journal of Financial Research, 19(2), 193-207. https://doi.org/10.1111/j.1475-6803.1996.tb00593.x

Alam, N. (2017). Analysis of the impact of select macroeconomic variables on the Indian stock market: A heteroscedastic cointegration approach. Business and Economic Horizons, 13(1), 119-127. https://doi.org/10.15208/beh.2017.09

Al-hajj, E., Al-Mulali, U., \& Solarin, S. A. (2018). Oil price shocks and stock returns nexus for Malaysia: Fresh evidence from nonlinear ardl test. Energy Reports, 4, 624-637. https://doi.org/10.1016/j.egyr.2018.10.002

Alqaralleh, H. (2019). Asymmetric sensitivities of house prices to housing fundamentals: evidence from UK regions. International Journal of Housing Markets and Analysis, 12(3), 442-455. https://doi.org/10.1108/IJHMA-06-2018-0047

Alqaralleh, H. (2020). Stock return-inflation nexus; revisited evidence based on nonlinear ARDL. Journal of Applied Economics, 23(1), 66-74. https://doi.org/10.1080/15140326.2019.1706828

Balcilar, M., Gupta, R., \& Miller, S. M. (2015). The out-of-sample forecasting performance of non-linear models of regional housing prices in the U.S. Applied Economics, 47, 2259-2277. https://doi.org/10.1080/00036846.2015.1005814

Balke, N. S., \& Fomby, T. B. (1997). Threshold cointegration. International Economic Review, 627-645. https://doi.org/10.2307/2527284

Balvers, R. J., Cosimano, T. F., \& McDonald, B. (1990). Predicting stock returns in an efficient market. Journal of Finance, 45, 1109-1128. https://doi.org/10.1111/j.1540-6261.1990.tb02429.x

Bernanke, B., \& Gertler, M. (2000). Monetary policy and asset price volatility (No. w7559). National Bureau of Economic Research. https://doi.org/10.3386/w7559

Bjørnland, H. C., \& Leitemo, K. (2009). Identifying the interdependence between US monetary policy and the stock market. Journal of Monetary Economics, 56(2), 275-282. https://doi.org/10.1016/j.jmoneco.2008.12.001

Brock, W. A., \& Hommes, C. H. (1998). Heterogeneous beliefs and routes to chaos in a simple asset pricing model. Journal of Economic Dynamics and Control, 22(8-9), 1235-1274. https://doi.org/10.1016/S0165-1889(98)00011-6

Cabrera, J. F., Wang, T., \& Yang, J. (2011). Linear and nonlinear predictability of international securitized real estate returns: a reality check. Journal of Real Estate Research, 33, 565-594.

Canepa, A., Chini, E. Z., \& Alqaralleh, H. (2020). Global cities and local housing market cycles. The Journal of Real Estate Finance and Economics, 61(4), 671-697. https://doi.org/10.1007/s11146-019-09734-8

Chen, M. H., Kim, W. G., \& Kim, H. J. (2005). The impact of macroeconomic and non-macroeconomic forces on hotel stock returns. International Journal of Hospitality Management, 24(2), 243-258. https://doi.org/10.1016/j.ijhm.2004.06.008

Chen, N. F., Roll, R., \& Ross, S. A. (1986). Economic forces and the stock market. Journal of Business, 383-403. https://doi.org/10.1086/296344

Cho, S. Y., Lee, C., \& Pfeiffer Jr, R. J. (2013). Corporate social responsibility performance and information asymmetry. Journal of Accounting and Public Policy, 32(1), 71-83. https://doi.org/10.1016/j.jaccpubpol.2012.10.005

Christie, A. A. (1982). The stochastic behavior of common stock variances: Value, leverage and interest rate effects. 
Journal of Financial Economics, 10(4), 407-432. https://doi.org/10.1016/0304-405X(82)90018-6

Chuang, I. Y., Lu, J. R., \& Tswei, K. (2007). Interdependence of international equity variances: evidence from East Asian markets. Emerging Markets Review, 8(4), 311-327. https://doi.org/10.1016/j.ememar.2007.08.001

Dasgupta, R. (2012). Long-run and short-run relationships between bse sensex and macroeconomic variables. International Research Journal of Finance and Economics, 95, 135-150.

Dijk, D. V., Teräsvirta, T., \& Franses, P. H. (2002). Smooth transition autoregressive models-a survey of recent developments. Econometric Reviews, 21(1), 1-47. https://doi.org/10.1081/ETC-120008723

Dimitrova, D. (2005). The relationship between exchange rates and stock prices: Studied in a multivariate model. Issues in Political Economy, 14(1), 3-9.

Enders, W., \& Siklos, P. L. (2001). Cointegration and threshold adjustment. Journal of Business \& Economic Statistics, 19(2), 166-176. https://doi.org/10.1198/073500101316970395

Fama, E. F. (1965). The behavior of stock-market prices. The Journal of Business, 38(1), 34-105.

Fama, E. F. (1981). Stock returns, real activity, inflation, and money. The American Economic Review, 71(4), 545-565. https://doi.org/10.1086/294743

Fama, E. F., \& French, K. R. (1989). Business conditions and expected returns on stocks and bonds. Journal of Financial Economics, 25(1), 23-49. https://doi.org/10.1016/0304-405X(89)90095-0

Farrell Jr, J. L. (1985). The dividend discount model: A primer. Financial Analysts Journal, 41(6), 16-25. https://doi.org/10.2469/faj.v41.n6.16

Ferson, W. E., \& Harvey, C. R. (1993). The risk and predictability of international equity returns. Review of Financial Studies, 6, 527-566. https://doi.org/10.1093/rfs/6.3.527

Franses, P. H., \& Van Dijk, D. (2000). Non-linear time series models in empirical finance. Cambridge University Press. https://doi.org/10.1017/CBO9780511754067

Gan, C., Lee, M., Yong, H. H. A., \& Zhang, J. (2006). Macroeconomic variables and stock market interactions: New Zealand evidence. Investment Management and Financial Innovations, 3(4), 89-101.

Granger, C. W., \& Terasvirta, T. (1993). Modelling non-linear economic relationships. OUP Catalogue.

Granger, C. W., \& Teräsvirta, T. (1999). A simple nonlinear time series model with misleading linear properties. Economics Letters, 62(2), 161-165. https://doi.org/10.1016/S0165-1765(98)00228-6

Guidolin, M., Orlov, A. G., \& Pedio, M. (2018). How good can heuristic-based forecasts be? A comparative performance of econometric and heuristic models for UK and US asset returns. Quantitative Finance, 18(1), 139-169. https://doi.org/10.1080/14697688.2017.1351619

Han, L., Li, Z., \& Yin, L. (2017). The effects of investor attention on commodity futures markets. Journal of Futures Markets, 37(10), 1031-1049. https://doi.org/10.1002/fut.21853

Harvey, D. I., \& Mills, T. C. (2001). Modelling global temperature trends using cointegration and smooth transitions. Statistical Modelling, 1(2), 143-159. https://doi.org/10.1177/1471082X0100100204

Ho, S. Y., \& Odhiambo, N. M. (2018). Analysing the macroeconomic drivers of stock market development in the Philippines. Cogent Economics \& Finance, 6(1), 1451265. https://doi.org/10.1080/23322039.2018.1451265

Hsieh, D. A. (1991). Chaos and nonlinear dynamics: application to financial markets. The Journal of Finance, 46(5), 1839-1877. https://doi.org/10.1111/j.1540-6261.1991.tb04646.x

Hubrich, K., \& Terasvirta, T. (2013). Thresholds and smooth transitions in vector autoregressive models. VAR Models in Macroeconomics - New Developments and Applications: Essays in Honor of Christopher A. Sims (Advances in Econometrics, Vol. 32, pp. 273-326). Emerald Group Publishing Limited. https://doi.org/10.1108/S0731-9053(2013)0000031008

Humpe, A., \& Macmillan, P. (2009). Can macroeconomic variables explain long-term stock market movements? A comparison of the US and Japan. Applied Financial Economics, 19(2), 111-119. https://doi.org/10.1080/09603100701748956

Ikoku, A. E. (2010). Is the stock market a leading indicator of economic activity in nigeria?. CBN Journal of Applied Statistics, 1(1), 17-38. 
Jamaludin, N., Ismail, S., \& Ab Manaf, S. (2017). Macroeconomic variables and stock market returns: Panel analysis from selected ASEAN countries. International Journal of Economics and Financial Issues, 7(1), 37-45.

Kapetanios, G. (2001). Model selection in threshold models. Journal of Time Series Analysis, 22(6), 733-754. https://doi.org/10.1111/1467-9892.00251

Kapetanios, G., Shin, Y., \& Snell, A. (2003). Testing for a unit root in the nonlinear STAR framework. Journal of Econometrics, 112(2), 359-379. https://doi.org/10.1016/S0304-4076(02)00202-6

Kwon, C. S., \& Shin, T. S. (1999). Cointegration and causality between macroeconomic variables and stock market returns. Global Finance Journal, 10(1), 71-81. https://doi.org/10.1016/S1044-0283(99)00006-X

Lamont, O. A. (2000). Investment plans and stock returns. The Journal of Finance, 55(6), 2719-2745. https://doi.org/10.1111/0022-1082.00304

Lardic, S., \& Mignon, V. (2008). Oil prices and economic activity: An asymmetric cointegration approach. Energy Economics, 30, 847-855. https://doi.org/10.1016/j.eneco.2006.10.010

Lee, B. S., \& Ryu, D. (2013). Stock returns and implied volatility: A new VAR approach. Economics: The $\begin{array}{lll}\text { Open-Access, } & \text { Open-Assessment } & \text { E-Journal, }\end{array}$ https://doi.org/10.5018/economics-ejournal.ja.2013-3

Lee, G., \& Ryu, D. (2018). Asymmetry in the stock price response to macroeconomic shocks: evidence from the Korean market. Journal of Business Economics and Management, 19(2), 343-359. https://doi.org/10.3846/jbem.2018.5563

Lin, F. L., Yang, S. Y., Marsh, T., \& Chen, Y. F. (2018). Stock and bond return relations and stock market uncertainty: evidence from wavelet analysis. International Review of Economics \& Finance, 55, 285-294. https://doi.org/10.1016/j.iref.2017.07.013

Liu, M. H., \& Shrestha, K. M. (2008). Analysis of the long-term relationship between macroeconomic variables and the Chinese stock market using heteroscedastic cointegration. Managerial Finance, 34(11), 744-755. https://doi.org/10.1108/03074350810900479

Luukkonen, R., Saikkonen, P., \& Teräsvirta, T. (1988). Testing linearity against smooth transition autoregressive models. Biometrika, 75(3), 491-499. https://doi.org/10.1093/biomet/75.3.491

McMillan, D. G. (2001). Nonlinear predictability of stock market returns: Evidence from nonparametric and threshold models. International Review of Economics \& Finance, 10(4), 353-368. https://doi.org/10.1016/S1059-0560(01)00093-4

Nazir, M. S., Nawaz, M. M., \& Gilani, U. J. (2010). Relationship between economic growth and stock market development. African Journal of Business Management, 4(16), 3473-3479.

Nishat, D. M., \& Shaheen, R. (2004). Macroeconomic Factors and Pakistani Equity Market. Pakistani Development Review, 43(4), 619-637. https://doi.org/10.30541/v43i4IIpp.619-637

Otero, J., \& Smith, J. (2017). Response surface models for OLS and GLS detrending-based unit-root tests in nonlinear ESTAR models. The Stata Journal, 17(3), 704-722. https://doi.org/10.1177/1536867X1701700310

Peters, E. E. (1994). Fractal market analysis: applying chaos theory to investment and economics (Vol. 24). John Wiley \& Sons.

Pilinkus, D., \& Boguslauskas, V. (2009). The short-run relationship between stock market prices and macroeconomic variables in Lithuania: an application of the impulse response function. Inžinerine Ekonomika, (5), 26-34.

Qi, M. (1999). Nonlinear predictability of stock returns using financial and economic variables. Journal of Business and Economic Statistics, 17(4), 419-429. https://doi.org/10.1080/07350015.1999.10524830

Ratanapakorn, O., \& Sharma, S. C. (2007). Dynamic analysis between the US stock returns and the macroeconomic variables. Applied Financial Economics, 17(5), 369-377. https://doi.org/10.1080/09603100600638944

Sakti, M., \& Harun, Y. (2013). Relationship between Islamis stock prices and macroeconomic variables: Evidence from Jakarta stock exchange Islamic index. Global Review of Islamic Economics and Business, 1(1), 71-84. https://doi.org/10.14421/grieb.2013.011-06

Sarantis, N. (2001). Nonlinearities, cyclical behaviour and predictability in stock markets: international evidence. International Journal of Forecasting, 17(3), 459-482. https://doi.org/10.1016/S0169-2070(01)00093-0 
Siliverstovs, B. (2005). The bi-parameter smooth transition autoregressive model. Economics Bulletin, 3(22), 1-11.

Singh, G. (2016). The Impact of Macroeconomic Fundamentals on Stock Prices Revised: A Study of Indian Stock Market. Journal of International Economics, 7(1), 76-91.

Sir, M. M. (2012). Impact of the macroeconomic variables on the stock market returns: The case of Germany and the United Kingdom. Global Journal of Management and Business Research, 12(16).

Teräsvirta, T. (1994). Specification, estimation, and evaluation of smooth transition autoregressive models. Journal of the American Statistical Association, 89(425), 208-218. https://doi.org/10.1080/01621459.1994.10476462

Teräsvirta, T., Van Dijk, D., \& Medeiros, M. C. (2005). Linear models, smooth transition autoregressions, and neural networks for forecasting macroeconomic time series: A re-examination. International Journal of Forecasting, 21(4), 755-774. https://doi.org/10.1016/j.ijforecast.2005.04.010

Timmermann, A. (2008). Elusive return predictability. International Journal of Forecasting, 24(1), 1-18. https://doi.org/10.1016/j.ijforecast.2007.07.008

Tripathy, N. (2011). Causal relationship between macroeconomic indicators and stock market in India. Asian Journal of Finance \& Accounting, 3(1), 208-226. https://doi.org/10.5296/ajfa.v3i1.633

Tsay, R. S. (1989). Testing and modeling threshold autoregressive processes. Journal of the American Statistical Association, 84(405), 231-240. https://doi.org/10.1080/01621459.1989.10478760

Ullah, F., Hussain, I., \& Rauf, A. (2014). Impacts of macroeconomy on stock market: Evidence from Pakistan. International Journal of Management and Sustainability, 3(3), 140-146.

Van Dijk, D. D. (1999). Smooth transition models: extensions and outlier robust inference (No. 200).

Yang, C., \& Zhou, L. (2016). Individual stock crowded trades, individual stock investor sentiment and excess returns. North American Journal of Economics and Finance, 38, 39-53. https://doi.org/10.1016/j.najef.2016.06.001

Yang, E., Kim, S. H., Kim, M. H., \& Ryu, D. (2018). Macroeconomic shocks and stock market returns: The case of Korea. Applied Economics, 50(7), 757-773. https://doi.org/10.1080/00036846.2017.1340574

Zhang, D. (2017). Oil shocks and stock markets revisited: measuring connectedness from a global perspective. Energy Economics, 62, 323-333. https://doi.org/10.1016/j.eneco.2017.01.009

\section{Copyrights}

Copyright for this article is retained by the author(s), with first publication rights granted to the journal.

This is an open-access article distributed under the terms and conditions of the Creative Commons Attribution license (http://creativecommons.org/licenses/by/4.0/). 